\title{
Biomarkers of resistance to immune checkpoint inhibitors in non-small-cell lung cancer: myth or reality?
}

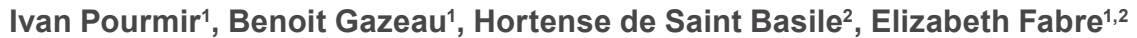 \\ 1Department of Thoracic oncology, Hôpital européen Georges Pompidou, Paris 75015, France. \\ ${ }^{2}$ INSERM U970, Université Paris Descartes Sorbonne Paris-Cité, Paris 75015, France.
}

Correspondence to: Dr. Elizabeth Fabre, Department of Thoracic oncology, Hôpital européen Georges Pompidou, INSERM U970, Université Paris Descartes Sorbonne Paris-Cité, Paris 75015, France. E-mail: elizabeth.fabre@aphp.fr

How to cite this article: Pourmir I, Gazeau B, de Saint Basile H, Fabre E. Biomarkers of resistance to immune checkpoint inhibitors in non-small-cell lung cancer: myth or reality? Cancer Drug Resist2020;3:276-86. http://dx.doi.org/10.20517/cdr.2020.14

Received: 17 Feb 2020 First Decision: 16 Mar 2020 Revised: 14 Apr 2020 Accepted: 23 Apr 2020 Available online: 11 May 2020

Science Editor: Gerhard Hamilton Copy Editor: Jing-Wen Zhang Production Editor: Jing Yu

\begin{abstract}
Immune checkpoint inhibitors represent a major therapeutic advance in non-small-cell lung cancer with several approved anti-programmed death-1 and anti-programmed death-L1 immunotherapies. A majority of patients however, will not respond to immune checkpoint inhibitors and display primary resistance while a subset of initially responsive patients will present secondary resistance. Thus, there is a crucial need for biomarkers to enable better prediction and diagnosis, and to overcome such resistance. Along with improvement in the understanding of immune escape, new biomarkers are being developed, including large scale proteomic, genomic and transcriptomic approaches in tumor and blood samples. We review the novel biomarkers that have been investigated in non-small-cell lung cancer and discuss how they can rationalize therapeutic strategies.
\end{abstract}

Keywords: Non-small-cell lung cancer, immune checkpoint inhibitors, resistance, predictive biomarkers, diagnostic biomarkers, programmed death ligand-1, tumor mutational burden, circulating tumor DNA

\section{INTRODUCTION}

Immune checkpoint inhibitors (ICI) such as programmed death-1 (PD-1) and programmed death ligand-1 (PD-L1) inhibitors represent a major breakthrough in the treatment of non-small cell lung cancer (NSCLC).

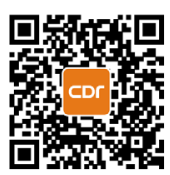


However, only $20 \%-30 \%$ of NSCLC patients respond to anti-PD-1/PD-L1 ${ }^{[1-5]}$. There is therefore a crucial need to integrate biomarkers of resistance for a more personalized approach to immunotherapy.

"Primary resistance" is found in patients who have never responded to ICI whereas "secondary/acquired resistance" is defined by tumor progression after prior response ${ }^{[6]}$. The efficacy of ICI relies on the derepression of immune checkpoints hindering the action of existing anti-tumor lymphocytes. Thus, several steps of the adaptive immune response need to be fulfilled: (1) production by tumor cells of tumor-specific antigens; (2) activation and expansion of T-cells specific for these antigens; (3) migration to and infiltration by effector T-cells of target cells; (4) recognition of target tumor cells; and (5) cytotoxic and immunostimulatory activity of the effector T-cells.

Mechanisms of resistance to ICI can impair each step of this immune response ${ }^{[7]}$. We review the existing and potential biomarkers to discuss which could serve as practical tools to predict or diagnose resistance to ICI.

\section{RESISTANCE BIOMARKERS RELATED TO INTRINSIC FACTORS OF TUMOR CELLS}

Mechanisms of intrinsic resistance include defects in immune recognition, cell signaling, gene expression and DNA damage responses. Emerging biomarkers are developed after considering these different mechanisms of resistance.

\section{Oncogenic PD-L1 expression}

Theoretically, the efficacy of ICI targeting the PD-1/PD-L1 axis relies on the de-repression of effector T-cells inhibited by the binding of PD-L1 on their membranes receptors. PD-L1 expression is currently the only validated biomarker in patients. Indeed, immunohistochemistry (IHC) staining of PD-L1 in tumor cells or immune cells is more frequently observed in responders to anti-PD-1/PD-L1 monoclonal antibody therapies ${ }^{[2-5,8]}$. However, even when a tumor displays > 50\% PD-L1 staining, half of NSCLC patients still have primary resistance to first line Pembrolizumab ${ }^{[8]}$. Conversely, clinical benefit is found in $10 \%$ of patients negative for $\mathrm{PD}-\mathrm{L}_{1}{ }^{[2,9]}$.

Historically, the development of ICI in NSCLC has been based on the PD-L1 status of tumor cells, specifically, via a tumor proportion score ${ }^{[8]}$, which is the percentage of viable tumor cells showing partial or complete membrane staining at any intensity. Given the rising role of PD-L1 expression on non-tumor cells, the use of a combined positivity score has been developed by taking into account the number of PD-L1 staining cells (tumor cells, lymphocytes, macrophages ${ }^{[10]}$ ). However, PD-L1 expression, whether on tumor cells or immune cells, still appears insufficient in predicting resistance. Other PD-1 ligands though, may be relevant to the clinical activity of ICI. The prevalence of programmed cell death-ligand 2 (PD-L2), the other known ligand of PD-1, has been investigated ${ }^{[11,12]}$. PD-L2 expression was correlated with treatment response using a cut-off value of $50 \%$ expression in tumor cells in NSCLC ${ }^{[1]}$.

Pre-analytical, analytical, and post-analytical aspects of PD-L1 IHC testing such as specimen type, size of samples, diversity of IHC antibodies, and lack of standardization of positivity cut-offs can all influence PD-L1 results ${ }^{[13,14]}$. Moreover, the intra-tumor heterogeneity of PD-L1 expression ${ }^{[15]}$ must be taken into account ${ }^{[8]}$ in anticancer treatment ${ }^{[16]}$.

\section{Lack of tumor immunogenicity}

Low tumor mutational burden, insufficient neo-antigens

Under certain conditions, mutations occurring in the genetic material of tumors can lead to the production of abnormal proteins, which can then be processed by the proteasome and antigen presenting machinery, resulting eventually in the presentation of immunogenic tumor specific neo-antigens ${ }^{[17]}$. Thus, it has been 
hypothesized that a higher frequency of non-synonymous mutations in tumor cells, the so called "tumor mutational burden (TMB)", should result in a higher rate of neo-antigen production and probability of triggering an adaptive immune response.

In NSCLC, a high, non-synonymous mutation burden is defined by a threshold superior to 178 mutations/ sample after whole exome sequencing (WES) and has been correlated to response, durable clinical benefit and progression-free survival. Conversely, a low TMB predicts poor efficacy in NSCLC patient cohorts and can be considered as a marker of primary resistance to $\mathrm{ICI}^{[18]}$. The association between TMB and response to ICI was demonstrated globally in a meta-analysis across 27 tumor types, including NSCLC ${ }^{[19]}$.

Multiple gene panels have also been used to evaluate the TMB in a more feasible way than WES with good accuracy $^{[20]}$. In Checkmate 227, a next generation sequencing (NGS) panel of 324 genes $^{[21]}$ was assessed by the FoundationOne CDx assay in NSCLC patients treated with the combination of Ipilimumab and Nivolumab. A good correlation between progression-free survival and TMB status was found using a threshold defined by 10 mutations/megabase.

TMB data have also been extracted from blood samples. The advantages of this approach are the convenience of blood sampling and a more global estimate of TMB given heterogeneity concerns in tissue samples ${ }^{[22]}$. Gandara et al. ${ }^{[22]}$ demonstrated the validity of TMB assessment in blood samples (bTMB) for predicting the response of metastatic NSCLC patients to Atezolizumab. The technique relied on the association of NGS of a large portion of cell-free DNA, allowing the identification and quantification of abnormal tumor sequences related to circulating tumoral DNA. In the MYSTIC study, metastatic NSCLC patients displaying a low bTMB (defined as $<16$ mutations/megabase in the Guardant Health Omni assay, a NGS panel of 500 genes $^{[23]}$ ) had lower overall survival under Durvalumab + Tremelimumab treatment compared to standard chemotherapy ${ }^{[2]]}$.

However, the CheckMate227 study failed to demonstrate correlation between overall survival and TMB and this revived debates about diagnostic techniques ${ }^{[25,26]}$. Beyond the crucial need to standardize practices (preanalytical parameters, thresholds, type of samples or sequencing methods), it has also been hypothesized that the TMB may not be a sufficient marker for predicting primary resistance to $\operatorname{ICI}^{[27,28]}$.

One should also keep in mind that mutations occurring in non-exonic regions of tumor DNA can lead to abnormal mRNA and peptide sequences, particularly via alternative splicing, thus generating potential neo-antigens that would not be predicted using the methods described above ${ }^{[29]}$. A refinement of TMB analysis could be neo-antigen burden assessment since only mutations resulting in the production of these immunogenic antigens would be relevant for predicting the existence of an adaptive anti-tumor response. Such an approach has been used in NSCLC via bioinformatics tools to enable calculation of neo-antigen load from genomic and transcriptomic data ${ }^{[30]}$. Indeed, a low neo-antigen burden has been associated with poor treatment response to anti-PD- ${ }^{[8,30]}$. McGranahan et al ${ }^{[30]}$ focused on the importance of the tumoral distribution of neo-antigenes and showed that clonal neo-antigens predominant in responders are more immunogenic than sub-clonal antigens.

\section{Loss of neo-antigens/immuno-editing}

Conversely, several mechanisms including immunoediting, can potentially lead to the loss of neo-antigens that enable primary responses to ICI, such that tumors develop secondary resistance. This phenomenon seems to be facilitated by the existence of intra-tumoral genomic heterogeneity, both at baseline and after PD-1 blockade ${ }^{[31]}$. Immunoediting has also been observed in NSCLC by dynamic blood sampling along anti-PD-1 therapy. The decrease in the number of circulating anti-tumor T-ell clones (see below "Clonality of tumor-specific T-cells") correlated with secondary resistance, suggesting a decrease in the number of neo-antigens stimulating the anti-tumor immune respons $\mathrm{e}^{[32]}$. 


\section{Oncogenic addiction}

Phase III trials have failed to demonstrate the efficacy of PD-1/PD-L1 monoclonal antibody in patients with EGFR and ALK mutations, which suggests the co-expression of inhibitory receptors or T-cell interactions with immunosuppressive cells ${ }^{[3-5]}$. EGFR results were summarized in a meta-analysis ${ }^{[33]}$. A retrospective study on patients receiving ICI monotherapy for advanced NSCLC with at least one oncogenic driver alteration (EGFR, BRAF, MET, HER2, ALK, RET, or ROS1), showed lower clinical activity compared with the KRAS group and the lack of response in cases of rearrangement ${ }^{[34]}$. In the subset of KRAS-mutated lung adenocarcinomas, co-mutation of the tumor suppressor gene STK11 is associated with a lack of response to $\mathrm{ICI}^{[35]}$.

Antigen presentation defect in tumor cells: loss of human leukocyte antigen expression

Events altering antigen presentation by the major histocompatibility class I complex (MHC-I) occur at a different level and are believed to prevent ICI efficacy. These include genetic, transcriptional, posttranscriptional and epigenetic mechanisms ${ }^{[36]}$. McGranahan et al ${ }^{[37]}$ applied a specifically designed computational method on DNA sequencing data from the HLA locus of NSCLC. They found a $40 \%$ prevalence of loss of heterozygosity in HLA class I alleles, impairing neo-antigen presentation by tumor cells. HLA loss of heterozygosity also seemed to be acquired heterogeneously in tumor sub-clones, as an adaptive mechanism in immune escape. This suggests that the assessment of HLA loss of heterozygosity could predict resistance in spite of a favorable tumor microenvironment and/or high TMB.

\section{Impaired cytotoxicity of effector T-cells}

Decreased interferon-gamma signaling. Interferon-gamma (IFN- $\gamma$ ) is produced by $\mathrm{CD} 8^{+} \mathrm{T}$-cells upon activation, as well as other inflammatory cells, and is a major effector of anti-tumor activity by enhancing the antigen-presentation machinery and having strong immune stimulatory properties. Defects in the IFN- $\gamma$ signaling pathway have been identified as a major mechanism of resistance ${ }^{[38]}$ to PD- 1 and CTLA-4 blockade ${ }^{[39]}$. It has been shown that genetic alterations of the Janus kinase/signal transducers and activators of transcription pathway ${ }^{[38,40]}$ can lead to secondarily PD-L1 negative tumor cells with altered antigen presentation. Therefore, transcriptomic analyses have been performed in order to identify a gene expression signature predictive of ICI efficacy. Panels of IFN- $\gamma$ signature genes have allowed prediction of responses of NSCLC patients to anti-PD-1/PD-L1 ${ }^{[41,42]}$. A decrease in the level of expression of these genes could be interpreted as a lack of $\mathrm{CD}^{+}$activity. Two different IFN- $\gamma$ signatures including respectively 8 and 4 genes showed a significant association with overall survival in NSCLC patients treated by anti-PD-L1 $1^{[41,43]}$. However, in lung and other types of cancer, results are contradictory ${ }^{[44-46]}$. It must be specified that IFN- $\gamma$ is also produced by a variety of inflammatory cells, leading to a transcriptional elevation of $I F N-\gamma$ genes and therefore, some imprecision in result interpretation. On the other hand, prolonged IFN- $\gamma$ stimulation leads to the expression of PD-L1, and thus, immune escape.

Production of immunosuppressive metabolites. The enzyme indole 2,3-dioxygenase (IDO) has an immunosuppressive activity in tumors and are associated with ICI resistance ${ }^{[47,48]}$. IDO expression, assessed by IHC, has commonly been found in NSCLC, notably in PDL-1 positive tumors ${ }^{[49]}$. Concentrations of these metabolites were measured with liquid chromatography and mass spectrometry ${ }^{[50]}$ and a higher kynurenine to tryptophan ratio and quinolinic acid at baseline, resulting from IDO metabolic activity, was found in plasma samples of NSCLC patients with early progression under Nivolumab treatment. To overcome this putative mechanism of resistance to ICI, the combination of ICI with IDO specific inhibitors are currently being evaluated in pre-clinical and human studies.

\section{RESISTANCE BIOMARKERS RELATED TO IMMUNE REACTION AND HOST FACTORS} Insufficiency of tumor-specific T-cell activation

Impaired T-cell trafficking to tumor cells and tumor infiltration

Chemokines regulate the infiltration of different immune cell subsets into tumors. As such, these molecules affect tumor immunity and can influence therapeutic outcomes in patients ${ }^{[51]}$. High levels of intra-tumoral 
chemokines such as CCL5, CXCL9, CXCL10 enhance the recruitment of T-cells into the tumor ${ }^{[52]}$ and preclinical studies in mice showed that infiltrating anti-tumor $\mathrm{CD}^{+}{ }^{+} \mathrm{T}$-cells are required for clinical response to anti-PD-1 treatment ${ }^{[53]}$. Similar studies in humans have shown that the pre-existing $\mathrm{CD} 8^{+}$ $\mathrm{T}$-cells in the tumor microenvironment correlate with response to anti-PD-1/PD-L1 therapies in various cancer types, including NSCLC ${ }^{[4,54,55]}$. Thus, the lack or paucity of T-cell infiltration of tumors characterizes the more general concept of "hot" and "cold" tumors with regard to the immune micro-environment ${ }^{[56]}$. The exclusion of T-cells involves multiple mechanisms such as the inhibition of T-cells attracting chemokines. In vivo, transforming growth factor beta, a multipotent immunosuppressive cytokine, suppresses $\mathrm{CD} 8^{+}$ T-cell expression of CXCR3 and limits their trafficking into tumors ${ }^{[57]}$.

The presence of intra-tumoral $\mathrm{CDs}^{+} \mathrm{T}$-cells is not always associated with clinical benefit however ${ }^{[44]}$. Therefore, there is growing interest to improve the identification of subsets of tumor-infiltrating lymphocytes (TILs) and tumor-specific lymphocytes. Herbst et al. ${ }^{[44]}$ propose that PD1 expressing CD ${ }^{+}$ T-cells, better select for patients responding to anti-PD-144. Clarke et al ${ }^{[58]}$ have reported that the number of tumor-resident $\mathrm{CD} 8{ }^{+} \mathrm{T}$-cells at baseline, and a $\mathrm{CD} 103^{+} \mathrm{CD} 49^{+} \mathrm{CD} 69^{+}$subset of TILs, are more predictive of response to anti-PD-1 therapy than total $\mathrm{CD}^{+}$T-cells in NSCLC and could be a potential marker of primary resistance to anti-PD-1 monotherapy.

\section{Clonality of tumor-specific T-cells}

It is now admitted that a restricted T-cell receptor sequence reflects the accumulation of TILs specific for a restricted number of tumor antigens at the invasive margins of the tumor. The sequencing of the T-cell receptor $\beta$-chain repertoire of TILs revealed that patients with a low "clonality" are more likely to respond to immunotherapy in several types of cancers ${ }^{[5,59,60]}$ using median clonality as a threshold.

\section{Impaired expansion of T-cells}

Expansion of anti-tumor specific T-cells following ICI therapy is a dynamic marker of treatment response and has recently been found to correlate with primary resistance to PD-1/PD-L1 blockade in metastatic NSCLC $^{[32]}$. However, the direct isolation and quantification of tumor-specific lymphocytes required a complex and customized process, given that the neo-antigen repertoire is unique. For this reason, indirect markers for measuring variations of this cell population could be more convenient.

\section{Alternative immune checkpoints}

The presence of $\mathrm{CD}^{+}$is not sufficient as they must be functional. Apart from PD-1, the expression of many alternative immune checkpoints can be found in NSCLC at baseline, or after prior blockade of the classic immune checkpoint pathways and are likely to contribute to primary or secondary resistance to ICI blockade ${ }^{[61]}$. The increased expression of TIM-3 (T-cell immunoglobulin and mucin domain 3), LAG-3 (lymphocyte activation gene 3), and BTLA (B and T lymphocyte attenuator) on CD8 ${ }^{+}$TILs are associated with adaptive resistance to anti-PD-1 in NSCLC ${ }^{[62-65]}$.

Fluorescence measurements of various immune checkpoints were also performed using blood samples. Non-responding patients showed a stability of fluorescence levels before and after the first cycle whereas responding patients displayed a dramatic decrease of CTLA-4, GITR (glucocorticoid-induced tumor necrosis factor receptor), and $\mathrm{OX} 40$ (CD134) expression on $\mathrm{CD}_{4}^{+}$and natural killers cells after the second cycle of immunotherapy ${ }^{[66]}$.

\section{Exhaustion of T-cells}

Exhausted T-cells demonstrate altered anti-tumor function and decreased re-invigoration potential under ICI, as well as an impaired capacity to generate T memory cells ${ }^{[7,67,68]}$. Terminally exhausted TILs are identified by the pattern of membrane markers with a high expression of CD38, CD101, and CD30 and low expression of $\mathrm{CD}^{[69]}$. The co-expression of multiple immune checkpoint receptors ${ }^{[63]}$ has been associated 
with a severely exhausted state and failure to rescue function with Nivolumab in vitro. These tumorinfiltrating but exhausted $\mathrm{CD}^{+}$cells could allow us to predict which patients would not respond to ICI because of terminal exhaustion ${ }^{[69]}$.

\section{Immunosuppressive cells}

Under certain conditions, the microenvironment favors the recruitment of immunosuppressive cells such as regulatory T-cells (Treg) and myeloid-derived suppressor cells, which induce the production of adenosine, an immunosuppressive molecule. The detection and quantification of several immunosuppressive cells within the tumor micro-environment is ongoing to assess their ability to predict ICI resistanc ${ }^{[7,70]}$. The quantification of Treg and myeloid-derived suppressor cells has also been analyzed to predict resistance to ICI in melanoma and gastric cancer ${ }^{[71-73]}$. No direct association has yet to be observed in NSCLC however.

\section{Resistance biomarkers related to the host: microbiota}

A strong immuno-modulatory effect of gut microbiota in the context of cancer has recently been reported. In the feces of NSCLC patients, the baseline paucity of several commensal bacteria species, after evaluation with a shotgun metagenomic analysis, has been associated with poor response to anti-PD-1 treatment. This could be reversed by fecal transplantation in a mouse model ${ }^{[74]}$. As for now, there is still a lack of congruence between the results of different studies correlating gut microbiota profiles to response to immune therapy to determine precisely which would be predictive of primary resistance, and would need to be modified for subsequent treatment ${ }^{[75]}$.

\section{DISCUSSION}

Resistance biomarkers are necessary at each stage of disease to define therapeutic strategies. Prior to the initiation of treatment, they are expected to rationalize the choice between monotherapy and combination therapy. During treatment, they are also needed to distinguish between radiological and pseudoprogression, and in cases of progression they are essential for personalized treatment.

From a short-term point of view, as the majority of patients currently eligible for ICI do not respond, such biomarkers would allow early cessation of and switching to another treatment. Notably, in the case of localized NSCLC, this would allow neoadjuvant immunotherapy without losing the opportunity of proceeding to surgery. In oligo-metastatic patients, the kinetics of sensitive biomarkers would also help in making decisions on complementary local treatment for complete cytoreduction. Lastly, an undetectable or dramatic decrease in systemic levels of biomarkers would allow suspending ICI safely in case of serious adverse events or persistent complete response.

Until now, the only validated marker to guide ICI prescription in NSCLC, outside of clinical trials, remains PD-L1 [Table 1]. As discussed above, this indicator is far from sufficient and still need to be refined and harmonized.

Currently, TMB appears as one of the potential biomarkers likely to guide future ICI prescriptions in the near future. The inter-individual diversity of alterations makes comprehensive approaches such as WES or analysis of large panels of genes increasingly attractive ${ }^{[21]}$. The speed of technical improvement in this field renders short-term routine exploitation realistic and should warrant consideration to spare obtaining sufficiently high amounts of tissue or blood from our current patients.

At the histopathological level, the increasing number of relevant cellular types to identify, coupled with the necessity of analyzing their spatial relationships, should lead us to multi-parametric in situ imaging methods such as $\mathrm{MIBI}^{[76]}$ or CODEX ${ }^{[77]}$. Multiplexed IHC represents a promising approach to analyze immune composition and define precisely $\mathrm{CDs}^{+}$cell subpopulations, location and functionality. 
Table 1. Predictive biomarkers for resistance to immune checkpoint inhibitors in NSCLC

\begin{tabular}{|c|c|c|c|c|c|}
\hline BioMarker & Treatment & Population & Methods & Findings associated with resistance & Ref. \\
\hline TMB & $\begin{array}{l}\text { Anti-PD-/PD-L1; } \\
\text { Anti-PD-1/PD-L1 + } \\
\text { anti-CTLA-4 }\end{array}$ & $\begin{array}{l}\text { Advanced } \\
\text { NSCLC }\end{array}$ & $\begin{array}{l}\text { WES; NGS gene panels; Tissue } \\
\text { and blood samples }\end{array}$ & $\begin{array}{l}\text { Low mutational burden correlates } \\
\text { with poor response, reduced OS and } \\
\text { PFS }\end{array}$ & {$[18,20,22,27]$} \\
\hline $\begin{array}{l}\text { Tumor } \\
\text { neoantigen } \\
\text { burden }\end{array}$ & Pembro & LUAD & WES, tissue samples & $\begin{array}{l}\text { Low neo-antigen burden correlates } \\
\text { with poor OS }\end{array}$ & {$[30]$} \\
\hline $\begin{array}{l}\text { Intra-tumor } \\
\text { neoantigen } \\
\text { heterogeneity }\end{array}$ & Pembro & $\begin{array}{l}\text { Early stage } \\
\text { NSCLC }\end{array}$ & WES; resected NSCLC & $\begin{array}{l}\text { High intra-tumor neo-antigen } \\
\text { heterogeneity correlates with poor } \\
\text { OS }\end{array}$ & {$[30]$} \\
\hline TILs & Pembro; Nivo & $\begin{array}{l}\text { Advanced } \\
\text { NSCLC }\end{array}$ & $\begin{array}{l}\text { Anti-CD4; anti-CD8 IHC } \\
\text { staining; tissue samples }\end{array}$ & $\begin{array}{l}\text { Low } C D 8^{+} T \text {-cells density and } C D 8^{+} / \\
C D 4^{+} \text {ratio correlate with poor } \\
\text { response }\end{array}$ & [44] \\
\hline PDL-1 & Anti-PD-1/PD-L1 & NSCLC & $\begin{array}{l}\text { Anti-PD-L1 IHC staining of } \\
\text { tumor cells, immune cells; } \\
\text { PDL1 mRNA; tissue samples }\end{array}$ & $\begin{array}{l}\text { Low PD-L1 density expression } \\
\text { predicts poor response, PFS and OS }\end{array}$ & {$[2,8,43]$} \\
\hline Alternative IC & Anti-PD-1/PD-L1 & NSCLC & $\begin{array}{l}\text { Multiparametric FACS } \\
\text { detecting alternative IC on } \\
\mathrm{CD}^{+} \text {TILs at baseline/after ICI }\end{array}$ & $\begin{array}{l}\text { Co-expression of alternative IC } \\
\text { is associated with primary and } \\
\text { secondary resistance }\end{array}$ & {$[61,62]$} \\
\hline IFN-y & $\begin{array}{l}\text { Pembro; Nivo; } \\
\text { Durva }\end{array}$ & $\begin{array}{l}\text { Advanced } \\
\text { NCLC }\end{array}$ & $\begin{array}{l}\text { Gene panels transcription; } \\
\text { tumor sample }\end{array}$ & $\begin{array}{l}\text { Decreased IFN- } \gamma \text { expression } \\
\text { correlates with poor response and OS }\end{array}$ & {$[41,42]$} \\
\hline IDO & Nivo & $\begin{array}{l}\text { Advanced } \\
\text { NCLC }\end{array}$ & $\begin{array}{l}\text { Liquid chromatography and } \\
\text { mass spectrometry; plasma } \\
\text { samples at baseline }\end{array}$ & $\begin{array}{l}\text { High kynurenine/tryptophan ratio } \\
\text { and quinolinic acid level associated } \\
\text { with poor response }\end{array}$ & {$[50]$} \\
\hline Microbiota & Nivo & $\begin{array}{l}\text { Advanced } \\
\text { NCLC }\end{array}$ & $\begin{array}{l}\text { Shotgun metagenomic analysis } \\
\text { of feces at baseline }\end{array}$ & $\begin{array}{l}\text { Low metagenomic species richness } \\
\text { and distinct profiles correlate with } \\
\text { poor response }\end{array}$ & {$[74]$} \\
\hline $\begin{array}{l}\text { Circulating } \\
\text { tumor-reactive } \\
\mathrm{CD} 8^{+} \text {clones }\end{array}$ & Pembro; Nivo & $\begin{array}{l}\text { Metastatic } \\
\text { NSCLC }\end{array}$ & $\begin{array}{l}\text { FACS on blood samples; TCR } \\
\text { sequencing }\end{array}$ & $\begin{array}{l}\text { Decreased number of circulating } \\
\text { clones correlates with secondary } \\
\text { resistance }\end{array}$ & [32] \\
\hline $\begin{array}{l}\text { Alternative } \\
\text { immune } \\
\text { checkpoints }\end{array}$ & Pembro; Nivo & $\begin{array}{l}\text { Advanced } \\
\text { NSCLC }\end{array}$ & $\begin{array}{l}\text { CTLA-4, GITR, and OX40 } \\
\text { fluorescence on CD } 4^{+} \text {and NK } \\
\text { cells; blood samples }\end{array}$ & $\begin{array}{l}\text { Stability of CTLA-4, GITR, and OX40 } \\
\text { fluorescence after 1st cycle correlates } \\
\text { with primary resistance }\end{array}$ & [66] \\
\hline
\end{tabular}

IC: immune checkpoints; NSCLC: non-small cell lung cancer; NK: natural killers; GITR: glucocorticoid-induced tumor necrosis factor receptor; TCR: T-cell receptor; IDO: indole 2,3-dioxygenase; OS: overall survival; ICI: immune checkpoint inhibitors; IFN- $\gamma$ : interferon-gamma; PD-L1: programmed death ligand-1; TILs: tumor-infiltrating lymphocytes; PFS: progression-free survival; IHC: immunohistochemistry; WES: whole exome sequencing; NGS: next generation sequencing; TMB: tumor mutational burden; FACS: fluorescence-activated cell sorting; LUAD: lung adenocarcinoma

In addition to the complexity of their immune composition, biomarkers must integrate immune changes during treatment. As an example, in a longitudinal study from Chen et al. ${ }^{[78]}$, sequential gene expression profiling of melanoma found no baseline difference between responders and non-responders to anti-PD-1 therapy, but hundreds of genes were then differentially expressed in early on-treatment biopsies. Therefore, repeated samplings represent a promising solution to assess the dynamic nature of treatment resistance and will probably remain key for treatment adaptation in patients responding to ICI. However, blood-based analysis represents a growing field of interest to achieve immune-monitoring. Other approaches using bronchoalveolar lavage fluid are in development to evaluate the local immune status at the site of lung cancer. This procedure may be performed during lung cancer diagnosis and repeated during therapy ${ }^{[79]}$.

The variety of biomarkers and resistance mechanisms discussed in this review [Table 1], and their cooccurrence at a single-patient-level, in addition to the growing number of available immunotherapies, emphasizes the necessity of including a much larger number of biological parameters in our strategies. This implies a shift in the scale of biological analyzes and techniques that are presently in use. Immunotherapy monitoring will certainly need both tissue and blood sampling and the combination of several biomarkers. Beside PD-L, other biomarkers are beginning to emerge: specific immune cell sub-populations analyzed by multiplexed IHC, plasmatic TMB, circulating immune cells and their antigenic repertoire.

Current advances including molecular profiling and specific tumor-associated immune characterization, allow us to hypothesize the following strategy: 
(1) Tissue and blood sampling with pathological and genomic analysis, all at baseline, in order to assess tumor immunogenicity and potential mechanisms of primary resistance;

(2) Determination of first line therapy: ICI monotherapy or combination;

(3) Early assessment of treatment efficacy and detection of primary resistance;

(4) Second line treatment or addition of supplementary antineoplastic compounds in case of primary resistance;

(5) Treatment pause or discontinuation when prolonged remission is achieved;

(6) Suspicion of clinical and radiological relapse and confirmation with systemic biomarker;

(7) Determination of optimal second line immunotherapy.

Several pre-requisite have yet to be fulfilled however, for new potential biomarkers to be routinely applied. The standardization of pre-analytic variables is also required ${ }^{[80]}$, as the definition of precise thresholds varies.

Evaluation of this exciting progress must also integrate the cost of innovation. The escalating health expenditure in cancer care in Western countries is of particular concern and the cost of performing biological tests must be taken into account. This requires an assessment of the overall spending related to cancer cases and one should not simply sum up the costs for the tests alone. Efficient biomarkers for monitoring disease status would also allow treatment discontinuation in cases of remission and subsequent economics. For example, the cost of WES for one individual has reached a lower order of magnitude than the cost for a single cycle of ICI therapy ${ }^{[81]}$.

\section{CONCLUSION}

The complexity of the immune system requires the combination of resistance biomarkers to define therapeutic strategies in NSCLC. A global approach integrating both immune and tumor-related parameters is needed. Novel composite and dynamic biomarkers of immune evasion are emerging to guide personalized immunotherapies. The simultaneous analysis of PD-L1 expression, specific anti-tumoral CD ${ }^{+}$ infiltration and TMB, seems a highly promising approach.

\section{DECLARATIONS}

\section{Authors' contributions}

Made substantial contributions to the drafting of the manuscript: Pourmir I, Fabre E, Gazeau B, de Saint Basile $\mathrm{H}$

Made contributions to the outlining and editing of the manuscript: Gazeau B, de Saint Basile H

\section{Availability of data and materials}

Not applicable.

\section{Financial support and sponsorship}

None.

\section{Conflicts of interest}

Elizabeth Fabre declares potential financial conflict of interest: Research grant (BMS), Honoraria (BMS, MSD, Roche), Consultancy, Speakers bureau (BMS, MSD), Travel accommodations-meetings (MSD), Board (Roche). Benoit Gazeau declares potential financial conflict of interest: Travel accommodationsmeetings (MSD). Hortense de Saint Basile declares potential financial conflict of interest: Research grants (BMS).

\section{Ethical approval and consent to participate}

Not applicable. 


\section{Consent for publication}

Not applicable.

\section{Copyright}

(c) The Author(s) 2020.

\section{REFERENCES}

1. Garon EB, Rizvi NA, Hui R, Leighl N, Balmanoukian AS, et al. Pembrolizumab for the treatment of non-small-cell lung cancer. N Engl J Med 2015;372:2018-28.

2. Brahmer J, Reckamp KL, Baas P, Crinò L, Eberhardt WE, et al. Nivolumab versus docetaxel in advanced squamous-cell non-small-cell lung cancer. N Engl J Med 2015;373:123-35.

3. Borghaei H, Paz-Ares L, Horn L, Spigel DR, Steins M, et al. Nivolumab versus docetaxel in advanced nonsquamous non-small-cell lung cancer. N Engl J Med 2015;373:1627-39.

4. Herbst RS, Baas P, Kim DW, Felip E, Pérez-Gracia JL, et al. Pembrolizumab versus docetaxel for previously treated, PD-L1-positive, advanced non-small-cell lung cancer (KEYNOTE-010): a randomised controlled trial. Lancet 2016;387:1540-50.

5. Rittmeyer A, Barlesi F, Waterkamp D, Park K, Ciardiello F, et al. Atezolizumab versus docetaxel in patients with previously treated nonsmall-cell lung cancer (OAK): a phase 3, open-label, multicentre randomised controlled trial. Lancet 2017;389:255-65.

6. Sharma P, Hu-Lieskovan S, Wargo JA, Ribas A. Primary, adaptive, and acquired resistance to cancer immunotherapy. Cell 2017;168:707-23.

7. Fares CM, Van Allen EM, Drake CG, Allison JP, Hu-Lieskovan S. Mechanisms of resistance to immune checkpoint blockade: why does checkpoint inhibitor immunotherapy not work for all patients? Am Soc Clin Oncol Educ Book 2019;39:147-64.

8. Reck M, Rodríguez-Abreu D, Robinson AG, Hui R, Csőszi T, et al.; KEYNOTE-024 Investigators. Pembrolizumab versus chemotherapy for PD-L1-positive non-small-cell lung cancer. N Engl J Med 2016;375:1823-33.

9. Carbognin L, Pilotto S, Milella M, Vaccaro V, Brunelli M, et al. Differential activity of nivolumab, pembrolizumab and MPDL3280A according to the tumor expression of programmed death-ligand-1 (PD-L1): sensitivity analysis of trials in melanoma, lung and genitourinary cancers. PLoS One 2015;10:e130142.

10. Kulangara K, Zhang N, Corigliano E, Guerrero L, Waldroup S, et al. Clinical utility of the combined positive score for programmed death ligand-1 expression and the approval of pembrolizumab for treatment of gastric cancer. Arch Pathol Lab Med 2019;143:330-7.

11. Takamori S, Takada K, Toyokawa G, Azuma K, Shimokawa M, et al. PD-L2 expression as a potential predictive biomarker for the response to Anti-PD-1 drugs in patients with non-small cell lung cancer. Anticancer Res 2018;38:5897-901.

12. Yearley JH, Gibson C, Yu N, Moon C, Murphy E, et al. PD-L2 expression in human tumors: relevance to anti-PD-1 therapy in cancer. Clin Cancer Res 2017;23:3158-67.

13. Lantuejoul S, Sound-Tsao M, Cooper WA, Girard N, Hirsch FR, et al. PD-L1 testing for lung cancer in 2019: perspective from the IASLC pathology committee. J Thorac Oncol 2020;15:499-519.

14. Kerr KM. The PD-L1 immunohistochemistry biomarker: two steps forward, one step back? J Thorac Oncol 2018;13:291-4.

15. Garon EB, Hellmann MD, Rizvi NA, Carcereny E, Leighl NB, et al. Five-year overall survival for patients with advanced non-small-cell lung cancer treated with pembrolizumab: results from the phase I KEYNOTE-001 study. J Clin Oncol 2019;37:2518-27.

16. Saleh R, Elkord E. Acquired resistance to cancer immunotherapy: role of tumor-mediated immunosuppression. Semin Cancer Biol July 2019:S1044-579X(19)30171-3.

17. Schumacher TN, Schreiber RD. Neoantigens in cancer immunotherapy. Science 2015;348:69-74.

18. Rizvi NA, Hellmann MD, Snyder A, Kvistborg P, Makarov V, et al. Mutational landscape determines sensitivity to PD-1 blockade in non-small cell lung cancer. Science 2015;348:124-8.

19. Yarchoan M, Hopkins A, Jaffee EM. Tumor mutational burden and response rate to PD-1 inhibition. N Engl J Med 2017;377:2500-1.

20. Rizvi H, Sanchez-Vega F, La K, Chatila W, Jonsson P, et al. Molecular determinants of response to anti-programmed cell death (PD)-1 and anti-programmed death-ligand 1 (PD-L1) blockade in patients with non-small-cell lung cancer profiled with targeted next-generation sequencing. J Clin Oncol 2018;36:633-41.

21. Frampton GM, Fichtenholtz A, Otto GA, Wang K, Downing SR, et al. Development and validation of a clinical cancer genomic profiling test based on massively parallel DNA sequencing. Nat Biotechnol 2013;31:1023-31.

22. Gandara DR, Paul SM, Kowanetz M, Schleifman E, Zou W, et al. Blood-based tumor mutational burden as a predictor of clinical benefit in non-small-cell lung cancer patients treated with atezolizumab. Nat Med 2018;24:1441-8.

23. Helman E, Artieri C, Vowles JV, Yen J, Nance T, et al. Abstract 5603: Analytical validation of a comprehensive 500-gene ctDNA panel designed for immuno-oncology and DNA damage research. Cancer Res 2018;78:5603.

24. ESMO immuno-oncology 2018: MYSTIC: first-line durvalumab with or without tremelimumab in metastatic NSCLC - The ASCO Post. Available from: https://www.ascopost.com/News/59583 [Last accessed on 26 Apr 2020]

25. Vokes NI, Liu D, Ricciuti B, Jimenez-Aguilar E, Rizvi H, et al. Harmonization of tumor mutational burden quantification and association with response to immune checkpoint blockade in non-small-cell lung cancer. JCO Precis Oncol 2019;3:10.1200/PO.19.00171.

26. Meléndez B, Campenhout CV, Rorive S, Remmelink M, Salmon I, et al. Methods of measurement for tumor mutational burden in tumor tissue. Transl Lung Cancer Res 2018;7:661.

27. Hellmann MD, Ciuleanu TE, Pluzanski A, Lee JS, Otterson GA, et al. Nivolumab plus ipilimumab in lung cancer with a high tumor 
mutational burden. N Engl J Med 2018;378:2093-104.

28. Bristol-Myers Squibb Reports Fourth Quarter and Full Year Financial Results | BMS Newsroom. Available from: https://news.bms.com/ press-release/corporatefinancial-news/bristol-myers-squibb-reports-fourth-quarter-and-full-year-fi-0 [Last accessed on 26 Apr 2020]

29. Park J, Chung YJ. Identification of neoantigens derived from alternative splicing and RNA modification. Genomics Inform 2019;17:e23.

30. McGranahan N, Furness AJ, Rosenthal R, Ramskov S, Lyngaa R, et al. Clonal neoantigens elicit T cell immunoreactivity and sensitivity to immune checkpoint blockade. Science 2016;351:1463-9.

31. Riaz N, Havel JJ, Makarov V, Desrichard A, Urba WJ, et al. Tumor and microenvironment evolution during immunotherapy with nivolumab. Cell 2017;171:934-49.e16.

32. Anagnostou V, Forde PM, White JR, Niknafs N, Hruban C, et al. Dynamics of tumor and immune responses during immune checkpoint blockade in non-small cell lung cancer. Cancer Res 2019;79:1214-25.

33. Lee CK, Man J, Lord S, Links M, Gebski V, et al. Checkpoint inhibitors in metastatic EGFR-mutated non-small cell lung cancer-a metaanalysis. J Thorac Oncol 2017;12:403-7.

34. Mazieres J, Drilon A, Lusque A, Mhanna L, Cortot AB, et al. Immune checkpoint inhibitors for patients with advanced lung cancer and oncogenic driver alterations: results from the IMMUNOTARGET registry. Ann Oncol 2019;30:1321-8.

35. Skoulidis F, Goldberg ME, Greenawalt DM, Hellmann MD, Awad MM, et al. STK11/LKB1 mutations and PD-1 inhibitor resistance in KRAS-mutant lung adenocarcinoma. Cancer Discov 2018;8:822-35.

36. Friedrich M, Jasinski-Bergner S, Lazaridou MF, Subbarayan K, Massa C, et al. Tumor-induced escape mechanisms and their association with resistance to checkpoint inhibitor therapy. Cancer Immunol Immunother 2019;68:1689-700.

37. McGranahan N, Rosenthal R, Hiley CT, Rowan AJ, Watkins TBK, et al. Allele-specific HLA loss and immune escape in lung cancer evolution. Cell 2017;171:1259-71.e11.

38. Shin DS, Zaretsky JM, Escuin-Ordinas H, Garcia-Diaz A, Hu-Lieskovan S, et al. Primary resistance to PD-1 blockade mediated by JAK1/2 mutations. Cancer Discov 2017;7:188-201.

39. Benci JL, Xu B, Qiu Y, Wu TJ, Dada H, et al. Tumor interferon signaling regulates a multigenic resistance program to immune checkpoint blockade. Cell 2016;167:1540-54.e12.

40. Zaretsky JM, Garcia-Diaz A, Shin DS, Escuin-Ordinas H, Hugo W, et al. Mutations Associated with Acquired Resistance to PD-1 Blockade in Melanoma. N Engl J Med 2016;375:819-29.

41. Higgs BW, Morehouse CA, Streicher K, Brohawn PZ, Pilataxi F, et al. Interferon gamma messenger RNA signature in tumor biopsies predicts outcomes in patients with non-small cell lung carcinoma or urothelial cancer treated with durvalumab. Clin Cancer Res 2018;24:3857-66.

42. Damotte D, Warren S, Arrondeau J, Boudou-Rouquette P, Mansuet-Lupo A, et al. The tumor inflammation signature (TIS) is associated with anti-PD-1 treatment benefit in the CERTIM pan-cancer cohort. J Transl Med 2019;17:357.

43. Fehrenbacher L, Spira A, Ballinger M, Kowanetz M, Vansteenkiste J, et al. Atezolizumab versus docetaxel for patients with previously treated non-small-cell lung cancer (POPLAR): a multicentre, open-label, phase 2 randomised controlled trial. Lancet 2016;387:1837-46.

44. Herbst RS, Soria JC, Kowanetz M, Fine GD, Hamid O, et al. Predictive correlates of response to the anti-PD-L1 antibody MPDL3280A in cancer patients. Nature 2014;515:563-7.

45. Hugo W, Zaretsky JM, Sun L, Song C, Moreno BH, et al. Genomic and transcriptomic features of response to anti-PD-1 therapy in metastatic melanoma. Cell 2016;165:35-44.

46. Ascierto ML, McMiller TL, Berger AE, Danilova L, Anders RA, et al. The intratumoral balance between metabolic and immunologic gene expression is associated with anti-PD-1 response in patients with renal cell carcinoma. Cancer Immunol Res 2016;4:726-33.

47. Toulmonde M, Penel N, Adam J, Chevreau C, Blay JY, et al. Use of PD-1 targeting, macrophage infiltration, and IDO pathway activation in sarcomas: a phase 2 clinical trial. JAMA Oncol 2018;4:93-7.

48. Holmgaard RB, Zamarin D, Munn DH, Wolchok JD, Allison JP. Indoleamine 2,3-dioxygenase is a critical resistance mechanism in antitumor T cell immunotherapy targeting CTLA-4. J Exp Med 2013;210:1389-402.

49. Volaric A, Gentzler R, Hall R, Mehaffey JH, Stelow EB, et al. Indoleamine-2,3-dioxygenase in non-small cell lung cancer: a targetable mechanism of immune resistance frequently coexpressed with PD-L1. Am J Surg Pathol 2018;42:1216-23.

50. Botticelli A, Cerbelli B, Lionetto L, Zizzari I, Salati M, et al. Can IDO activity predict primary resistance to anti-PD-1 treatment in NSCLC? J Transl Med 2018;16:219.

51. Nagarsheth N, Wicha MS, Zou W. Chemokines in the cancer microenvironment and their relevance in cancer immunotherapy. Nat Rev Immunol 2017;17:559-72.

52. Harlin H, Meng Y, Peterson AC, Zha Y, Tretiakova M, et al. Chemokine expression in melanoma metastases associated with CD8+ T-cell recruitment. Cancer Res 2009;69:3077-85.

53. Badoual C, Hans S, Merillon N, Van Ryswick C, Ravel P, et al. PD-1-expressing tumor-infiltrating T cells are a favorable prognostic biomarker in HPV-associated head and neck cancer. Cancer Res 2013;73:128-38.

54. Tumeh PC, Harview CL, Yearley JH, Shintaku IP, Taylor EJ, et al. PD-1 blockade induces responses by inhibiting adaptive immune resistance. Nature 2014;515:568-71.

55. Uryvaev A, Passhak M, Hershkovits D, Sabo E, Bar-Sela G. The role of tumor-infiltrating lymphocytes (TILs) as a predictive biomarker of response to anti-PD1 therapy in patients with metastatic non-small cell lung cancer or metastatic melanoma. Med Oncol Northwood Lond Engl 2018;35:25.

56. Bonaventura P, Shekarian T, Alcazer V, Valladeau-Guilemond J, Valsesia-Wittmann S, et al. Cold tumors: a therapeutic challenge for immunotherapy. Front Immunol 2019;10. 
57. Gunderson AJ, Yamazaki T, McCarty K, Fox N, Phillips M, et al. TGF $\beta$ suppresses CD $8^{+} \mathrm{T}$ cell expression of CXCR3 and tumor trafficking. Nat Commun 2020;11:1749.

58. Clarke J, Panwar B, Madrigal A, Singh D, Gujar R, et al. Single-cell transcriptomic analysis of tissue-resident memory T cells in human lung cancer. J Exp Med 2019;216:2128-49.

59. Funt S, Snyder Charen A, Yusko E, Vignali M, Benzeno S, et al. Correlation of peripheral and intratumoral T-cell receptor (TCR) clonality with clinical outcomes in patients with metastatic urothelial cancer (mUC) treated with atezolizumab. J Clin Oncol 2016;34:3005.

60. Schrama D, Ritter C, Becker JC. T cell receptor repertoire usage in cancer as a surrogate marker for immune responses. Semin Immunopathol 2017;39:255-68.

61. Watanabe N, Gavrieli M, Sedy JR, Yang J, Fallarino F, et al. BTLA is a lymphocyte inhibitory receptor with similarities to CTLA-4 and PD-1. Nat Immunol 2003;4:670-9.

62. Koyama S, Akbay EA, Li YY, Herter-Sprie GS, Buczkowski KA, et al. Adaptive resistance to therapeutic PD-1 blockade is associated with upregulation of alternative immune checkpoints. Nat Commun 2016;7:1-9.

63. Thommen DS, Schreiner J, Müller P, Herzig P, Roller A, et al. Progression of lung cancer is associated with increased dysfunction of T cells defined by coexpression of multiple inhibitory receptors. Cancer Immunol Res 2015;3:1344-55.

64. Cheng H, Borczuk A, Janakiram M, Ren X, Lin J, et al. Wide expression and significance of alternative immune checkpoint molecules, B7x and HHLA2, in PD-L1-negative human lung cancers. Clin Cancer Res 2018;24:1954-64.

65. Datar I, Sanmamed MF, Wang J, Henick BS, Choi J, et al. Expression analysis and significance of PD-1, LAG-3, and TIM-3 in human non-small cell lung cancer using spatially resolved and multiparametric single-cell analysis. Clin Cancer Res 2019;25:4663-73.

66. Du W, Hu S, Cai S, Wang Y, Wu L, et al. Dynamic testing of stimulative and suppressive biomarkers on peripheral blood cells at early stages of immunotherapy predicts response in advanced cancer patients. Discov Med 2018;25:277-90.

67. Wherry EJ, Kurachi M. Molecular and cellular insights into T cell exhaustion. Nat Rev Immunol 2015;15:486-99.

68. Pauken KE, Sammons MA, Odorizzi PM, Manne S, Godec J, et al. Epigenetic stability of exhausted T cells limits durability of reinvigoration by PD-1 blockade. Science 2016;354:1160-5.

69. Philip M, Fairchild L, Sun L, Horste EL, Camara S, et al. Chromatin states define tumor-specific T cell dysfunction and reprogramming. Nature 2017;545:452-6.

70. Gallimore A, Quezada SA, Roychoudhuri R. Regulatory T cells in cancer: where are we now? Immunology 2019;157:187-9.

71. Simpson TR, Li F, Montalvo-Ortiz W, Sepulveda MA, Bergerhoff K, et al. Fc-dependent depletion of tumor-infiltrating regulatory T cells co-defines the efficacy of anti-CTLA-4 therapy against melanoma. J Exp Med 2013;210:1695-710.

72. Kamada T, Togashi Y, Tay C, Ha D, Sasaki A, et al. PD-1+ regulatory T cells amplified by PD-1 blockade promote hyperprogression of cancer. Proc Natl Acad Sci 2019;116:9999-10008.

73. Meyer C, Cagnon L, Costa-Nunes CM, Baumgaertner P, Montandon N, et al. Frequencies of circulating MDSC correlate with clinical outcome of melanoma patients treated with ipilimumab. Cancer Immunol Immunother 2014;63:247-57.

74. Routy B, Le Chatelier E, Derosa L, Duong CPM, Alou MT, et al. Gut microbiome influences efficacy of PD-1-based immunotherapy against epithelial tumors. Science 2018;359:91-7.

75. Shaikh FY, Gills JJ, Sears CL. Impact of the microbiome on checkpoint inhibitor treatment in patients with non-small cell lung cancer and melanoma. EBioMedicine 2019;48:642-7.

76. Keren L, Bosse M, Marquez D, Angoshtari R, Jain S, et al. A structured tumor-immune microenvironment in triple negative breast cancer revealed by multiplexed ion beam imaging. Cell 2018;174:1373-87.e19.

77. Goltsev Y, Samusik N, Kennedy-Darling J, Bhate S, Hale M, et al. Deep profiling of mouse splenic architecture with CODEX multiplexed imaging. Cell 2018;174:968-81.e15.

78. Chen PL, Roh W, Reuben A, Cooper ZA, Spencer CN, et al. Analysis of immune signatures in longitudinal tumor samples yields insight into biomarkers of response and mechanisms of resistance to immune checkpoint blockade. Cancer Discov 2016;6:827-37.

79. Domagala-Kulawik J, Skirecki T, Dziedzic D, Polubiec-Kownacka M, Kryczka T, et al. Do two lungs form an integrated immune system? Learning from BALF examination in lung cancer. Ann Oncol 2019;30.

80. Magaki S, Hojat SA, Wei B, So A, Yong WH. An introduction to the performance of immunohistochemistry. Methods Mol Biol 2019;1897:289-98.

81. Schwarze K, Buchanan J, Taylor JC, Wordsworth S. Are whole-exome and whole-genome sequencing approaches cost-effective? A systematic review of the literature. Genet Med 2018;20:1122-30. 